\title{
Modelo de ajuste nos governos petistas em meio à ideologia da conciliação de classes: chão histórico do Golpe de 2016 no Brasil Contemporâneo
}

Model of adjustment in PT administrations amid the ideology of class conciliation: historical ground of the 2016 coup in contemporary Brazil

\author{
Alba Maria Pinho de Carvalho* \\ Natan dos Santos Rodrigues Júnior**
}

\begin{abstract}
Resumo - Nesta produção acadêmica, o foco analítico incide no modelo de ajuste encarnado nos governos petistas, enfatizando a ideologia da conciliação de classes como sustentáculo desta versão do modelo rentistaneoextrativista, no período em que o PT ocupou a presidência da República. Enfocamos, de modo especial, o momento de hibridização das políticas de ajuste com o chamado neodesenvolvimentismo, resgatando polêmicas ideológicas que demarcam esta perspectiva do neodesenvolvimento no século XXI. Para circunscrever este período da contemporaneidade brasileira, efetivamos um recuo histórico, contemplando os percursos do ajuste do Brasil ao capitalismo financeirizado, em seus diferentes ciclos. Sustentamos a tese de um esgotamento da versão petista desse modelo de ajuste com a debacle desta ideologia da conciliação de classes, a marcar o cenário de meados da segunda década do século XXI, a partir da ofensiva das próprias elites, deflagrando, assim, a crise brasileira contemporânea, chão histórico do Golpe de 2016.

Palavras-chave: Ideologia da conciliação de classes; ajuste brasileiro; governos petistas; neodesenvolvimentismo; golpe de 2016.

Abstract - This paper's analytical focus is the model of adjustment embodied by the PT administrations, emphasizing the ideology of class conciliation as the basis for this version of the rentierist/neo-extractivist model. We focus specially on the moment of hybridization of policies of adjustment with the so-called neo-developmentism, rescuing ideological controversies that circumscribe this perspective of the neo-development
\end{abstract}

\footnotetext{
*Doutora em Sociologia, professora do Departamento de Ciências Sociais da Universidade Federal do Ceará UFC, integrando o corpo docente do Programa de Pós-Graduação em Sociologia PPGS e dos Mestrados Acadêmico e Profissional em Avaliação de Políticas Públicas da UFC. Coordenadora da Rede Universitária de Pesquisadores sobre América Latina - RUPAL. E-mail: albapcarvalho@gmail.com. ORCID: http://orcid.org/0000-0002-35003792.

** Mestre em Sociologia pela Universidade Federal do Ceará - UFC. Bacharel e Licenciado em Ciências Sociais pela Universidade Estadual do Ceará - UECE. Integrante da Rede Universitária de Pesquisadores sobre América Latina - RUPAL e do Centro de Estudos do Trabalho e Ontologia do Ser Social - CETROS. E-mail: natan.srj@ gmail.com. ORCID: http://orcid.org/0000-0002-1293-9715.
} 


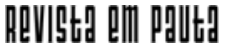

\} MODELO DE AJUSTE NOS GOVERNOS - CARVALHO, A. M. P.; RODRIGUES JÚNIOR, N. S. \}

DOI: $10.12957 /$ REP.2019.45245

in the 21 st century. In order to circumscribe this period of Brazilian contemporaneity, we made a historical retreat, contemplating the paths of Brazil's adjustment to financially-oriented capitalism in its different cycles. We support the thesis of an exhaustion of the PT version of this model of adjustment with the debacle of this ideology of class conciliation, marking the scenario of the mid-2010s, from the offensive by the elites themselves, thus triggering the contemporary Brazilian crisis, ground zero of the 2016 Coup.

Keywords: ideology of class conciliation; Brazilian adjustment; PT administrations; neo-developmentism; 2016 coup.

\section{Introdução}

O golpe parlamentar, midiático e jurídico que depôs a presidenta eleita Dilma Rousseff (Partido dos Trabalhadores - PT), alçando o até então vice-presidente Michel Temer (Movimento Democrático Brasileiro - MDB) ao comando do Executivo Federal, representa uma ofensiva restauradora do neoliberalismo, no contexto de aprofundamento da crise brasileira contemporânea (RODRIGUES JR.; CARVALHO, 2018). É o esgotamento do modelo social-liberal de conciliação de classes, encarnado pelos governos petistas, que assumem manter as políticas de ajuste ao capitalismo financeirizado, articulando-as às políticas de enfrentamento à pobreza e, em um segundo momento, também hibridizando-as com o chamado neodesenvolvimentismo. É a debacle da ideologia que circunscreve o modelo de ajuste petista, a marcar o cenário de meados da segunda década do século XXI, a partir da ofensiva das próprias elites.

O Governo Temer implementa uma agenda regressiva, ao pôr em prática o desmonte de direitos sociais e trabalhistas, em um ritmo deveras avassalador, intensificando a superexploração da força de trabalho - característica estrutural das formações histórico-sociais dependentes (MARINI, 2005). A rigor, este governo emergente do Golpe de 2016 agrava os processos de "dependência redobrada", no dizer de Leda Paulani (2012b).

Neste contexto do Golpe 16, nos percursos de desmonte do Estado democrático de direito, emerge, na cena política brasileira, a chamada "nova direita", com significativas articulações com a direita tradicional, no âmbito do Executivo, do Legislativo e do Judiciário. Esta respalda-se nos espaços 


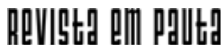

\} MODELO DE AJUSTE NOS GOVERNOS - CARVALHO, A. M. P.; RODRIGUES JÚNIOR, N. S. \}

DOI: $10.12957 /$ REP.2019.45245

da considerada "grande mídia" e com ocupação dominante nas redes sociais, em uma aliança com Igrejas cristãs neopentecostais, difusoras de um fundamentalismo religioso, a beirar um "fascismo sociocultural". Assim, forças de extrema-direita conseguem ganhar as eleições presidenciais de 2018, alçadas, então, à presidência da República, com expressiva força na Câmara Federal e no Senado, bem como com o recorrente apoio do Judiciário. Este avanço da extrema-direita também se revela em nível de segmento expressivo de Estados da Federação brasileira.

É este o contexto do fenômeno sociopolítico designado por "bolsonarismo", caracterizado, justamente, pelo radical desmonte do Estado democrático de direito, para além de qualquer pacto liberal civilizatório. É a implementação de um capitalismo selvagem, nos marcos do ultraneoliberalismo, destituindo quaisquer modos de regulação democrática e buscando, de todas as formas, esvaziar e/ou eliminar espaços institucionais de expressão de forças democráticas da sociedade civil. A nosso ver, este momento-limite da história brasileira de dominância da extrema-direita é o coroamento, a culminância do Golpe de 2016, urdido no chão histórico da crise brasileira contemporânea.

Para o desvendamento analítico deste cenário-limite da vida brasileira, marcado pela negação de quaisquer mediações com a própria democracia liberal, precisamos fazer um recuo histórico no tempo, remontando à década de 1990, quando do ajuste do Brasil ao capitalismo financeirizado, a prolongar-se por quase 30 anos (1990-2019). É a experiência de ajuste brasileiro, nos seus diferentes ciclos (CARVALHO; MILANEZ; GUERRA, 2018; CARVALHO, 2017a, 2017b). Para efeito de nossa análise, centramos o olhar nos ciclos de ajuste dos governos petistas, para circunscrever dimensões fundantes da crise brasileira e do Golpe de 2016.

Indiscutivelmente, a crise contemporânea brasileira constitui o chão histórico onde se gesta, toma amplitude e se consolida o Golpe 2016 (CARVALHO, 2018). Esta crise, deflagrada em 2013, a partir das chamadas "Jornadas de Junho" de contestação aos ciclos de ajuste petista, constitui, antes de tudo, uma expressão peculiar, no contexto do Brasil do Ajuste, da crise do capital, manifesta em 2008. Tal crise é caracterizada como crise do próprio sistema do capital, de caráter sistêmico, de longa duração e de amplitude global ${ }^{1}$. Nesta perspectiva, avalia Carta Maior (2011, p. 1) que se trata de uma "crise estrutural profunda e cada vez mais grave que necessita da adoção de remédios abrangentes, a fim de alcançar uma solução sustentável". Em verdade, ao longo de mais de dez anos (2008-2019), o sistema do capital não conseguiu uma solução para esta crise, que se prolonga e se desdobra em novas configurações, deslocando-se geograficamente dos países centrais para a periferia (HARVEY, 2011). Assim, na segunda década

\footnotetext{
1 Nas trilhas de analistas marxistas, com especial destaque para István Mészásos (2009), esta crise do capital, emergente na primeira década do século XXI, particulariza-se em relação às crises anteriores do capitalismo,por ser uma crise estrutural, a atingir o sistema sociometabólico do capital.
} 


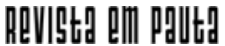

\} MODELO DE AJUSTE NOS GOVERNOS - CARVALHO, A. M. P.; RODRIGUES JÚNIOR, N. S. \}

DOI: $10.12957 /$ REP.2019.45245

dos anos 2000, tal crise estrutural do capital chega à América Latina e, em particular, ao Brasil.

Especificamente, a crise contemporânea brasileira é o esgotamento da versão petista do modelo de ajuste, com base na conciliação de classes, expressa nos dois governos Lula e no primeiro governo de Dilma Rousseff. Assim, impõem-se as configurações deste modelo de ajuste brasileiro, em curso desde 1990, a encarnar uma dupla dependência: o modelo rentistaneoextrativista ${ }^{2}$. A rigor, tal modelo articula, de forma orgânica, os interesses e as formas de acumulação de dois segmentos do capital: capital rentista e capital vinculado ao novo extrativismo mineral e vegetal, privilegiando o agronegócio e a mineração (CARVALHO, 2017a, 2017b). Desse modo, vivencia-se, há quase três décadas, o chamado "ajuste estrutural brasileiro", com base na chamada ideologia neoliberal (HARVEY, 2016), compreendendo inflexões a circunscrever diferentes ciclos de ajuste (CARVALHO; GUERRA, 2015).

Ao longo da década de 1990, a ideologia neoliberal, materializada nos governos de ajuste, sobretudo na "Era FHC", é alvo de crítica sistemática, desenvolvida por importantes movimentos sociais e organizações políticas, sob a liderança do PT e da Central Única dos Trabalhadores (CUT). Ao assumir o governo, em 2003, o PT, envolto em uma ampla política de alianças, inclusive com partidos e políticos representantes dos interesses do capital e de segmentos conservadores, assume as diretrizes e mecanismos macroeconômicos das chamadas políticas de ajuste, reeditando a ideologia neoliberal, com determinadas inflexões (CARVALHO; GUERRA, 2015, 2016).

Uma destas inflexões, especificamente a partir do segundo Governo Lula, é a sustentação da exigência do crescimento econômico, mantendo as políticas macroeconômicas de ajuste. É desta simbiose entre neoliberalismo e busca da aceleração do crescimento econômico que emergem as bases ideológicas do neodesenvolvimentismo petista ${ }^{3}$.

De fato, este modelo advogava a possibilidade de um desenvolvimento econômico com inclusão social, em meio à crise do capital, que atendesse aos "interesses da nação", em uma versão marcada pela conciliação de classes. Indiscutivelmente, essa "conciliação de classes" privilegia os interesses do capital, contemplando, de forma pontual, demandas imediatas dos setores mais pobres e miseráveis da classe trabalhadora. A ideologia dos governos petistas proclamava que esse é um modelo em que "todos ganham", escamoteando o fato de que "todos ganham", mas de forma eminentemente desigual, reproduzindo, assim, a desigualdade estrutural da formação social brasileira, em meio à diminuição dos índices de pobreza.

\footnotetext{
${ }^{2}$ Modelo centrado na financeirização dependente e no extrativismo intensivo de riquezas, em uma reedição contemporânea do modelo extrativista primário-exportador (CARVALHO; GUERRA, 2015).

${ }^{3}$ Chamamos de "neodesenvolvimentismo petista" esta versão peculiar da aceleração do crescimento no século XXI, assumida no segundo Governo Lula e no primeiro Governo Dilma Rousseff, com configurações distintas do modelo desenvolvimentista do século XX.
} 


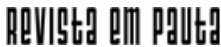

\} MODELO DE AJUSTE NOS GOVERNOS - CARVALHO, A. M. P.; RODRIGUES JÚNIOR, N. S.

DOI: $10.12957 /$ REP.2019.45245

\section{A inserção subordinada do Brasil ao capitalismo financeirizado: constituição do modelo de ajuste no final do século XX e limiar do século XXI}

Para pensar e refletir sobre a ideologia do modelo de ajuste nos governos petistas, focando, de modo específico, no neodesenvolvimentismo, se faz necessário situá-la nos percursos da inserção do país ao capitalismo mundializado. Ao longo de 29 anos (1990-2019), o Brasil está a vivenciar a chamada experiência de ajuste estrutural, implementando um modelo que acirra a sua dependência no cenário mundial do sistema do capital na contemporaneidade.

Os circuitos do ajuste são deflagrados em 1990, com a inserção do Brasil ao capitalismo financeirizado, demarcando a entrada tardia do país nos processos de ajuste da América Latina, no contexto de mundialização do capital, com dominância financeira (CHESNAIS, 1996).

É um processo, hoje, de quase três décadas do que denominamos "Brasil do Ajuste", com diferentes inflexões. Carvalho e Guerra (2015, 2016, 2018), em produções de meados da segunda década do século XXI, fazem um esforço analítico para categorizar o que denominam diferentes ciclos de ajuste brasileiro. Para elas, há cinco ciclos de ajuste na experiência brasileira, quais sejam: 1 - ciclo de estabilização da economia, compreendendo os governos Collor de Mello (1990-1992), Itamar Franco (1992-1994) e Fernando Henrique Cardoso (1995-1998; 1999-2002); 2 - ciclo de consolidação das políticas de ajuste e de reconstituição do mercado interno de consumo de massas, compreendendo o primeiro Governo Lula (2003-2006) e parte do segundo (2007-2008); 3 - ciclo de articulação de políticas de ajuste e neodesenvolvimentismo, a partir da segunda metade do segundo Governo Lula (2009-2010) e primeiro Governo Dilma Rousseff (2011-2014); 4 - ciclo de retomada da ortodoxia rentista, em um ajuste à direita, que se dá com o segundo Governo Dilma, interrompido pelo impeachment; 5 - ciclo da submissão radical ao financismo e desmonte de direitos, pela via do Golpe de 2016, no Governo Temer (2016-2018) (CARVALHO, 2006, 2018).

A rigor, a partir da última década do século $X X$, mais precisamente em 1990, o Brasil assume uma inserção ativa e dependente ao capitalismo financeirizado, com a efetiva participação do Estado, ao empreender a financeirização dos processos de acumulação em articulação com o agronegócio e a mineração extrativista. Nesta perspectiva, o Estado brasileiro adota, na íntegra, o receituário neoliberal imposto pelo Consenso de Washington, deflagrando o que pode ser considerado um primeiro ciclo de ajuste (CARVALHO; GUERRA, 2015).

De fato, a implementação da Agenda de Washington, no contexto brasileiro, tem início tardiamente, com a vitória de Fernando Collor de Melo na disputa eleitoral de 1989. A eleição de Fernando Henrique Cardoso (FHC) para a presidência da República, em 1995, e a sua reeleição para um segundo 


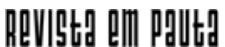

\} MODELO DE AJUSTE NOS GOVERNOS - CARVALHO, A. M. P.; RODRIGUES JÚNIOR, N. S. \}

DOI: $10.12957 /$ REP.2019.45245

mandato, em 1998, representou a consolidação da agenda neoliberal em seus pilares: abertura econômica, privatização e desregulamentação do Estado. Trata-se de um ciclo específico de ajuste marcado pela estabilização da economia, durante toda a década de 1990 e limiar dos anos 2000.

Esta adoção subordinada da Agenda de Ajuste de Washington, imposta pelas instituições multilaterais - FMI e Banco Mundial - implica um processo de desindustrialização do país e a reprimarização da pauta de exportação brasileira, no âmbito de políticas macroeconômicas que transformam o Brasil em uma "plataforma de valorização financeira" (PAULANI, 2012a), com pagamento de juros exorbitantes nos circuitos da financeirização da economia. Desse modo, delineia-se e consolida-se, no país, o modelo de ajuste rentista-neoextrativista, vigente na América Latina, a assumir marcadas especificidades no contexto brasileiro.

Neste contexto de adoção ativa e subordinada do ideário neoliberal, o país vivenciou ampla redução do assalariamento formal, em especial no setor secundário, resultado da política de desindustrialização nos percursos da experiência de ajuste brasileiro. De 1994 a 2000, o desemprego no Brasil passou de 4,5 milhões para 11,5 milhões de trabalhadores respectivamente, alcançando uma taxa de desemprego de 15\% (POCHMANN; BORGES, 2002). Flexibilização e expansão da informalização dos postos de trabalho tiveram, como resultado, a precarização ainda maior dos empregos assalariados de carteira assinada no país.

Em uma avaliação deste período histórico de dominância da ideologia neoliberal, nos marcos de um Estado Ajustador, que "ajusta e ajustase aos ditames do capital" (CARVALHO, 2006), consubstanciado sobretudo na "Era FHC", o Brasil contemporâneo vivencia o período, até então mais intenso, de ajuste ao capitalismo financeirizado. O programa do Governo FHC (1995-2002) define as condições fundamentais para o ingresso ativo do país na era da financeirização. Indiscutivelmente, este tempo histórico de consolidação do neoliberalismo é marcado por cortes de recursos públicos, a expropriarem verbas que poderiam assegurar políticas sociais na materialização de direitos conquistados na Constituição de 1988.

Neste contexto, forças progressistas e de esquerda, alinhadas aos movimentos sociais, com destaque para a CUT e o Movimento dos SemTerra (MST), empreendem formas de resistência que, se não conseguem barrar as reformas neoliberais, mantêm tais reformas dentro de determinados limites, na defesa de direitos trabalhistas e sociais. É um momento de tensionamento explícito das formas de resistência no enfrentamento ao neoliberalismo, na versão brasileira do ajuste.

Ao final do século XX e limiar do século XXI, o projeto neoliberal demonstrava sinais de desgaste, como uma tendência mundial, a perpassar a civilização contemporânea do capital. Tal desgaste, decorrente dos baixos índices de crescimento econômico e aumento da concentração de renda nas frações mais ricas das classes dominantes locais e internacionais, acirra 


\section{REVIIStg alm PDUtI}

\} MODELO DE AJUSTE NOS GOVERNOS - CARVALHO, A. M. P.; RODRIGUES JÚNIOR, N. S. \}

DOI: $10.12957 /$ REP.2019.45245

a desigualdade, desemprego, pobreza e violência. São estes indicadores de uma crise do neoliberalismo, com expressões diferenciadas em países da América Latina, no deflagrar dos anos 2000.

Neste cenário, importantes lutas sociais desenvolveram-se em todo o mundo, como os movimentos antiglobalização, em Seattle (1999), as configurações do Fórum Social Mundial, a partir de 1999, e, ainda, revoltas populares nas periferias do sistema. Especificamente na América Latina, emergem e difundem-se processos de intensa mobilização, em resposta a debacle das políticas neoliberais. Tais processos de articulação e organização resultam na eleição de governos progressistas e de esquerda, que assumem, então, com maior ou menor intensidade, agendas antineoliberais, configurando o que, à época, foi denominado de "virada à esquerda" (CARVALHO, 2006). Dentre estes governos, cabe destacar: Hugo Chávez, na Venezuela; Evo Morales, na Bolívia; Rafael Correa, no Equador; e Luís Inácio Lula da Silva, no Brasil.

Diante do desgaste do neoliberalismo, a grande burguesia internacional realizou ajustes em sua estratégia: o Estado passou a intervir nas "falhas do mercado", buscando inserir, de forma precária e pontual, segmentos expropriados nos circuitos de expansão sem limites do capital.

No caso do Brasil, tal modelo acirrou a dependência brasileira ao sistema do capital e foi mantido e consolidado nos 13 anos de governos petistas de Lula (2003-2010) e de Dilma Rousseff (2011-2016), em uma versão de conciliação de classes.

\section{A ideologia da conciliação de classes nos governos petistas: o neodesenvolvimentismo em meio à consolidação das políticas de ajuste}

Mészáros (2004, p. 65, grifos no original), na obra $O$ poder da ideologia, circunscreve elementos analíticos deveras fecundos para pensar a ideologia na civilização contemporânea do capital:

Na verdade, a ideologia não é uma ilusão nem superstição religiosa de indivíduos mal orientados, mas uma forma específica de consciência social, materialmente ancorada e sustentada. Como tal, não pode ser superada nas sociedades de classe. Sua persistência se deve ao fato de ela ser constituída objetivamente (e constantemente reconstituída) como consciência prática inevitável das sociedades de classe...

Movimentando estas pistas de Mészáros (2004) para refletir sobre os posicionamentos ideológicos dos governos petistas, percebemos que os direcionamentos dados ao modelo de ajuste, sobremodo nos governos de Lula, bem revelam a perspectiva de viabilizar uma regulação dos conflitos de classe por diferentes vias. Tais vias complementam-se no sentido de cons- 


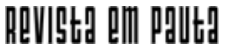

\} MODELO DE AJUSTE NOS GOVERNOS - CARVALHO, A. M. P.; RODRIGUES JÚNIOR, N. S. \}

DOI: $10.12957 /$ REP.2019.45245

truir um pacto de adesão: privilegiamento dos interesses dos setores dominantes do capital, consignados no modelo rentista-neoextrativista, quais sejam, setores do capital financeiro e do capital vinculado ao agronegócio e à mineração; atendimento de demandas emergenciais dos segmentos pauperizados, buscando administrar as expressões da pobreza, no contexto contemporâneo de uma massa de sobrantes a habitar as margens; valorização dos trabalhadores assalariados, com a formalização do emprego e aumentos reais do salário-mínimo; e absorção, no aparelho de Estado, de segmentos da burocracia sindical e da direção de movimentos sociais 4 .

A rigor, é fincando-se nesta perspectiva de regulação dos conflitos de classe que os governos petistas assumem a ideologia da conciliação de classes, como uma "forma específica de consciência social, materialmente ancorada e sustentada" (MÉSZÁROS, 2004, p. 65). A materialização desta ideologia assume configurações diferenciadas ao longo dos 13 anos de governos petistas, permitindo identificar ciclos distintos de ajuste ${ }^{5}$. O primeiro Governo Lula (2003-2006) consolida as políticas macroeconômicas de ajuste da "Era FHC", hibridizando-as com as chamadas "políticas de enfrentamento à pobreza", a encarnar diferentes estratégias: aumento real do salário-mínimo com repercussões efetivas aos benefícios previdenciários indexados a este salário-mínimo; acesso popular ao crédito bancário; Bolsa Família como projeto socioassistencial extremamente ampliado, a atingir populações pobres e extremamente pobres nas periferias urbanas e no meio rural, chegando aos mais distintos grotões do país.

Assim, nesta versão lulista do modelo de ajuste, são incontestes os crescentes ganhos do capital rentista e do capital vinculado ao neoextrativismo agrícola e mineral, mas, também, são inegáveis mudanças na estrutura de classes, com a ascensão social dos miseráveis e extremamente pobres. A rigor, mantém-se e amplia-se a desigualdade estrutural, em meio à diminuição dos índices de pobreza.

Trata-se de um novo momento histórico no Brasil, a inserir-se nesta chamada "virada à esquerda" no Continente Latino-Americano, com configurações peculiares de um governo de ajuste, conduzidas por um presidente oriundo das lutas de oposição e de resistências. Longe de enfrentar e/ ou tensionar com os interesses do capital, avança na consolidação das políticas neoliberais, no âmbito de um "reformismo sem reformas estruturais". Como bem sintetiza Francisco de Oliveira (2007), tem-se, no Brasil de Lula, processos de uma "hegemonia às avessas" ${ }^{\text {. }}$. Carvalho e Guerra (20015, p. 50) assim circunscrevem este ciclo petista de ajuste:

\footnotetext{
${ }^{4}$ Ruy Braga (2016), ao discutir o fenômeno configurado como lulismo, bem explicita estas concessões efetivas, mesmo que modestas, aos trabalhadores, como base de um consentimento aos governos petistas.

${ }^{5}$ Ver categorização dos ciclos de ajuste nas produções de Carvalho e Guerra, em publicações de 2015, 2016 e 2018.

${ }^{6}$ Francisco de Oliveira (2007) denomina de hgemonia às avessas a este curioso fenômeno em que parte "dos de baixo" dirige o Estado por intermédio do programa "dos de cima".
} 
No século XXI, em meio aos circuitos da crise, em seus permanentes deslocamentos e às redefinições geopolíticas mundiais, consolida-se a posição brasileira no cenário mundial como emergente plataforma internacional da valorização financeira, a garantir ganhos inigualáveis ao capital financeiro, mediante elevação das taxas de juro, no âmbito de uma política monetária e cambial de ajuste (PAULANI, 2012a; 2012b7). Este é o segundo ciclo de ajuste a se consubstanciar no primeiro e em parte do segundo governo Lula, que, de um lado, segue à risca a política macroeconômica de ajuste e, de outro, investe em políticas de enfrentamento à pobreza, garantindo uma inserção social passiva das massas pela via do consumo.

Em verdade, mantém-se e aprofunda-se a inserção brasileira dependente ao capitalismo mundializado, circunscrita como "era de servidão financeira" $^{\prime 8}$ (OLIVEIRA; BRAGA; RIZEK, 2010), efetivando-se, no dizer de Ruy Braga (2010, p. 7), uma "forma sui generis de dominação social que se enraizou no Brasil". Carlos Nelson Coutinho (2010, p. 32) configura este ciclo petista como uma "hegemonia da pequena política", quando a política deixa de ser pensada como arena de luta por diferentes projetos de sociedade e passa, portanto, a ser vista como terreno alheio à vida cotidiana dos simples indivíduos, como administração do existente. Neste segundo ciclo de ajuste do primeiro Governo Lula e parte do segundo, o país consegue atingir patamares de crescimento consideráveis no contexto do ajuste neoliberal.

Com efeito, a expansão dos mercados financeiros globais e a elevação dos preços das commodities, produzidas na América Latina, somadas às escolhas políticas do Governo Lula, criaram um ambiente favorável ao crescimento econômico com baixa inflação, embora aquém dos demais países emergentes ${ }^{9}$. De fato, na política econômica mantém-se orientações neoliberais, mas operam-se variações no modelo, obtendo resultados positivos em termos de crescimento econômico, geração de emprego e rendimento dos trabalhadores e estruturação de políticas assistenciais para os estratos mais vulneráveis da população, quando comparado aos números da década de 1990 (MACÁRIO; RODRIGUES JR.; SILVA, 2016).

Os últimos dois anos do segundo Governo Lula e o primeiro Governo Dilma Rousseff (2011-2014) demarcam uma inflexão do modelo brasileiro ao capitalismo financeirizado. A rigor, deflagra-se um terceiro ciclo de ajuste, marcado por uma tentativa de hibridização da política macroeconômica neoliberal com o chamado neodesenvolvimentismo (CARVALHO; GUERRA, 2015). A ideologia da conciliação de classes assume uma nova configuração, numa tentativa de ampliar o pacto com as elites, envolvendo também os setores empresariais, em troca de consideráveis incentivos ao

\footnotetext{
${ }^{7}$ Ver Paulani , 2012a, 2012b).

${ }^{8}$ Esta configuração está delineada no título do livro de 2010 da Boitempo, organizado por Francisco de Oliveira, Ruy Braga e Cibele Rizek, qual seja, "Hegemonia às avessas: economia, política e cultura na era da servidão financeira.

${ }_{9}^{9}$ A esse respeito, conferir Brasil em desenvolvimento: Estado, planejamento e políticas públicas (IPEA, 2009).
} 


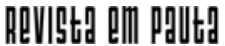

\} MODELO DE AJUSTE NOS GOVERNOS - CARVALHO, A. M. P.; RODRIGUES JÚNIOR, N. S. \}

DOI: $10.12957 /$ REP.2019.45245

capital. Mantém-se a perspectiva da adesão passiva das massas, consolidando as "políticas de enfrentamento à pobreza" como via estratégica. Desse modo, amplia-se ainda mais o Bolsa Família e criam-se outros programas socioassistenciais, como o Minha Casa, Minha Vida, a atender a grande demanda popular por moradia, ao mesmo tempo em que são beneficiados os setores do capital vinculado à construção civil.

Esta política do neodesenvolvimentismo no Brasil do Ajuste visa, estrategicamente, afirmar a posição do país no cenário internacional como potência emergente, respaldado no considerável crescimento brasileiro, no âmbito do chamado modelo de "crescimento com inclusão". Nesta perspectiva, cabe destacar o protagonismo do Brasil na construção dos Brics, como uma alternativa de integração dos países do Sul Global, para além da dominância dos EUA.

Este chamado neodesenvolvimentismo brasileiro, no limiar da segunda década do século XXI, vem envolto em uma perspectiva ideológica que parece mesclar elementos do desenvolvimentismo do século XX com noções e ideias peculiares ao ajuste estrutural do país. Assim, à época, esta proposição neodesenvolvimentista desencadeou uma polêmica sobre a natureza desta proposta: um segmento de analistas enveredou por uma discussão do neodesenvolvimentismo como uma terceira via de ajuste ao capitalismo mundializado; outro segmento de pesquisadores discute o neodesenvolvimentismo como uma via de ampliação do neoliberalismo, em uma combinação, de fato, sui generis do modelo brasileiro de ajuste. Em verdade, o neodesenvolvimentismo no século XXI provoca a emergência de uma grande diversidade de discursos ideológicos relativamente autônomos no plano da consciência social (MÉSZÁROS, 2004).

Luiz Carlos Bresser-Pereira (2006, p. 12) foi um dos primeiros a teorizar sobre esta atualização do desenvolvimentismo no âmbito do Estado brasileiro como um terceiro caminho:

O novo desenvolvimentismo é, ao mesmo tempo, um 'terceiro discurso', entre o discurso populista e o da ortodoxia convencional, e o conjunto de diagnósticos e ideias que devem servir de base para a formulação, por cada Estado-Nação, da sua estratégia nacional de desenvolvimento. É um conjunto de propostas de reformas institucionais e de políticas econômicas, por meio das quais as nações de desenvolvimento médio buscam, no inicio do século XXI, alcançar os países desenvolvidos.

Neste aporte ideológico fica patente a concepção do neodesenvolvimentismo como um caminho alternativo ao neoliberalismo. Ademais, são retomadas ideias das décadas de 1940-1950, segundo as quais seria possível às nações periféricas alcançarem o padrão de desenvolvimento dos países centrais. É esta uma concepção de teóricos próximos aos governos petistas, a diluírem a perspectiva do modelo de ajuste neoliberal, assumido pelo Brasil e outros países da América Latina. Giovanni Alves (2016) coloca este 


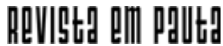

\} MODELO DE AJUSTE NOS GOVERNOS - CARVALHO, A. M. P.; RODRIGUES JÚNIOR, N. S. \}

DOI: $10.12957 /$ REP.2019.45245

neodesenvolvimentismo no centro da crítica, vinculando-o a uma forma de privilegiamento dos interesses do capital monopolista, no contexto da crise. Segundo Alves (2016, p. 114), o neodesenvolvimentismo seria "[...] uma outra visão de desenvolvimento capitalista na periferia do sistema-mundo do capital", com forte atuação do Estado, visando criar as condições para o crescimento da economia, bem como para o fortalecimento do mercado interno, com redução dos níveis de pobreza e políticas distributivas.

A nosso ver, esta tentativa de hibridização das políticas de ajuste com neodesenvolvimentismo é uma alternativa buscada pelos governos petistas para garantir crescimento econômico em um contexto internacional desfavorável ao modelo rentista-neoextrativista, bem diferente do cenário extremamente favorável do primeiro Governo Lula. Nesta perspectiva, o Estado brasileiro é chamado a assumir uma função crucial, seja como financiador, a exemplo da relação do Banco Nacional de Desenvolvimento Econômico e Social (BNDES) com as grandes corporações de capital privado nacional, seja como investidor, como se manifestou, por exemplo, no Programa de Aceleração do Crescimento (PAC). É desta simbiose entre neoliberalismo e busca da aceleração do crescimento econômico que emergem as bases ideológicas do neodesenvolvimentismo petista.

Esta articulação híbrida do neoliberalismo e do neodesenvolvimentismo não conseguiu se afirmar na vida brasileira. De fato, os setores produtivos, os empresários, não aderiram às proposições de desenvolvimento propugnadas pelo governo petista, na gestão Dilma Rousseff. Luís Carlos Bresser-Pereira (2006, p. 13), nas suas elucubrações sobre o novo desenvolvimentismo, já alerta para a exigência de um consenso interno:

Um consenso pleno é impossível, mas um consenso que una empresários do setor produtivo, trabalhadores, técnicos do governo e classes médias profissionais - um acordo nacional, portanto - está, hoje, em processo de formação, aproveitando o fracasso da ortodoxia convencional.

A rigor, este acordo nacional em torno do neodesenvolvimentismo não se estabelece, limitando-se às proposições governamentais. O capital financeiro, em articulação com o capital vinculado ao segmento do neoextrativismo, permanece como a base do modelo, mantendo lucros exorbitantes, em meio à crise que marca o final do primeiro Governo Dilma. Esta crise, inclusive, é uma expressão do fracasso da simbiose entre neoliberalismo e neodesenvolvimentismo, traduzindo-se em taxas ínfimas de crescimento e volta da inflação.

Conformando uma tendência histórica, a conciliação de classes, assumida, em diferentes configurações, pelos governos petistas, começa a ruir, em meio à crise do capital que chega à América Latina e, especificamente, ao Brasil, fragilizando as bases de sustentação do modelo rentistaneoextrativista na versão petista. Um marco de deflagração da crise do modelo petista de ajuste são as rebeliões de 2013 - as chamadas "Jornadas 


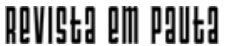

\} MODELO DE AJUSTE NOS GOVERNOS - CARVALHO, A. M. P.; RODRIGUES JÚNIOR, N. S. \}

DOI: $10.12957 /$ REP.2019.45245

de Junho" -, que explicitam e publicizam as contradições deste modelo, fazendo emergir, na cena brasileira, um desejo difuso de mudança, devidamente explorado por uma extrema-direita a ganhar visibilidade pública. A crise contemporânea brasileira assume configurações econômicas e políticas que se interpenetram, criando condições para uma ruptura comandada pelas elites.

No campo específico das configurações políticas da crise, ganha destaque a desarticulação da chamada base de apoio do governo no Congresso Nacional. Neste sentido, o segundo mandato de Dilma Rousseff é um período de acirramento e desmonte de pactos sociopolíticos. A rigor, Dilma Rousseff inicia o seu segundo governo, em 2015, com a imposição de uma agenda neoliberal, marcada por dura austeridade e cortes em investimentos públicos. Com esta radical inversão do programa de governo petista, sustentado na campanha, deflagra-se um quarto ciclo de ajuste, assim circunscrito por Carvalho e Guerra (2016, p. 272-273):

[...] um ajuste à direita, a retomar a ortodoxia das políticas de ajuste, nos marcos da financeirização dependente e dos processos de acumulação por espoliação, a privilegiar os interesses do capital, sem quaisquer limites do que pode ser nomeado de democracia de mercado.

Segundo Leda Paulani (2016, p. 73-74), "esse novo e fatal erro derrubou de vez a economia (o ano de 2015 fechou com queda de 3,8\% no PIB e enorme elevação do desemprego) e abriu espaço político para a contestação do segundo mandato da presidente". A aplicação de medidas alinhadas à ortodoxia neoliberal, em 2015, pelo segundo Governo Rousseff, não foi suficiente para barrar a articulação das elites do capital, face à crise em curso. Estava em processo o golpe parlamentar-midiático-jurídico que depôs a presidenta democraticamente eleita, sem os devidos motivos jurídicos. Um golpe que atenta contra a democracia e instaura dimensões de um Estado de Exceção ${ }^{10}$.

\section{Debacle da ideologia da conciliação de classes: Golpe de 2016 no contexto da crise contemporânea brasileira}

A necessária compreensão da debacle da ideologia da conciliação de classes, no Brasil da segunda década do século XXI, exige adentrar as configurações peculiares da crise contemporânea brasileira, considerando o contexto geopolítico determinante desta crise, chão histórico do Golpe de 2016.

\footnotetext{
${ }^{10}$ Importante registrar que o golpe institucional ocorrido no Brasil não é uma anomalia na política internacional. Em tempos de crise estrutural do capital é perceptível o aumento da ação de grupos de extrema-direita, a efetivarem rupturas democráticas em diversas partes do mundo, em especial na América Latina, como nos casos de Honduras (2009) e Paraguai (2012), bem como as tentativas de desestabilização na Venezuela.
} 


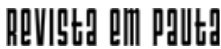

\} MODELO DE AJUSTE NOS GOVERNOS - CARVALHO, A. M. P.; RODRIGUES JÚNIOR, N. S. \}

DOI: $10.12957 /$ REP.2019.45245

Neste esforço explicativo, uma primeira demarcação a considerar é a expansão da crise estrutural do capital para os países dependentes em todo o mundo ao final da primeira década do século XXI e limiar da segunda. Uma das expressões da expansão desta crise para América Latina é, precisamente, a queda dos preços das commodities e a retração do investimento internacional, pilares do atual padrão exportador de especialização produtiva no continente latino-americano (OSÓRIO, 2012). É esta uma questão geopolítica, a atingir diretamente a própria conformação do modelo brasileiro de ajuste rentista-neoextrativista. A rigor, em um contexto internacional desfavorável, sobretudo em relação à posição da China - importante destino das exportações brasileiras de commodities -, teve início a erosão das condições objetivas do pacto de classes no Brasil.

Assim, esboça-se uma crise no cenário brasileiro, levando as elites, vinculadas aos segmentos do capital rentista e neoextrativista, a urdir uma ruptura do pacto sustentador da ideologia petista da conciliação de classes. Em verdade, as elites do capital, em um contexto de crise, não aceitaram restringir os seus lucros exorbitantes e, assim, articulam, como saída estratégica, a ruptura com o chamado social-liberalismo petista. Isso implica romper com qualquer perspectiva de conciliação de classes, assumindo, de forma intensiva, a ortodoxia neoliberal.

Afirma Carvalho (2018) que estamos diante do esgotamento da versão petista do modelo rentista-neoextrativista, fincado na ideologia da conciliação de classes. É a debacle do pacto de classes, rompido pelas elites, com as forças do governo em uma posição defensiva, querendo manter, a qualquer custo, pactos já desfeitos nos conluios palacianos.

O Golpe de Estado de 2016 bem consubstancia a alternativa das forças do capital para manter as taxas de lucro, no contexto de crise. Nesta perspectiva, o governo de Michel Temer, emergente do golpe, opta por uma versão do modelo rentista-neoextrativista alicerçado na superexploração da força de trabalho, com desmonte de direitos e conquistas dos trabaIhadores, atingindo fortemente os segmentos pauperizados. E, assim, constituiu-se o cenário político da ofensiva neoliberal restauradora, fundada na radicalização das políticas neoliberais, no desmonte de direitos sociais, na espoliação das riquezas nacionais e no desmanche de políticas públicas, penalizando, fortemente, a classe trabalhadora. Como afirma Ruy Braga (2016, p. 60),

[...] as forças golpistas derrubaram o governo não pelo que Dilma Rousseff concedeu aos setores populares, mas por aquilo que ela não foi capaz de entregar aos empresários; um ajuste fiscal ainda mais radical, que exigiria alterar a Constituição Federal, uma reforma previdenciária regressiva e o fim da proteção trabalhista.

Ao longo da pesada arquitetura do Golpe 2016, foi efetivamente desestruturada a lógica de cidadania fundante do texto constitucional, com 


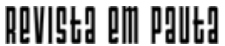

\} MODELO DE AJUSTE NOS GOVERNOS - CARVALHO, A. M. P.; RODRIGUES JÚNIOR, N. S. \}

DOI: $10.12957 /$ REP.2019.45245

a imposição da lógica do financismo. De acordo com Giovanni Alves (2017, p. 104):

O desmonte da Nação implica em abolir direitos conquistados nas últimas décadas vinculados ao projeto de civilização brasileira. Desmontar a CLT e abolir a parte social da Constituição de 1988 faz parte do conjunto de reformas neoliberais do governo Temer visando satisfazer os interesses do bloco neoliberal no poder (burguesia rentista-parasitária hegemônica com aliança com a burguesia agroexportadora, e a burguesia interna, que se beneficia das benesses do Estado, capturado pelos interesses rentistas).

De fato, os três anos do Governo Temer, nos circuitos do Golpe de 2016, deflagraram um desmonte da nação brasileira, desarticulando três grandes pactos marcantes na vida brasileira: o pacto getulista, consubstanciado na CLT e desmontado com a contrarreforma trabalhista; o pacto da Constituição de 1988, de afirmação de direitos sociais via políticas públicas, que tem expressão emblemática de desmonte na Emenda Constitucional 95, a congelar por 20 anos os gastos com políticas sociais; o pacto lulista, com a desarticulação das políticas de enfrentamento à pobreza e o retorno dos índices de pobreza e miséria, superados nos governos petistas.

A rigor, o golpe institucional de 2016 representa uma nova inflexão no projeto das classes dominantes no Brasil. Em meio a um aprofundamento da crise estrutural do capital, afirmou-se, como marca do sistema do capital contemporâneo, o retorno à ortodoxia do neoliberalismo, sem concessões mínimas aos segmentos dos trabalhadores. Neste contexto, está em marcha:

A imposição de uma nova configuração de Estado, de caráter conservador e autoritário, com um crescente fechamento democrático. É um Estado submetido aos interesses do financismo, nos marcos de uma exacerbação de neoliberalismo, com um amplo retrocesso no campo dos direitos sociais e trabalhistas que remontam a um Brasil de 80 anos atrás, um Brasil pré-Vargas! (CARVALHO, 2017b, p. 3-4).

Este golpe culmina com a ascensão da extrema-direita ao poder, conformando o fenômeno do "bolsonarismo", a partir de uma perigosa combinação de ultraneoliberalismo, de militarismo e de reacionarismo políticosocial, a instaurar tempos sombrios de obscurantismo e barbárie.

\section{Considerações finais}

O Brasil, ao final da segunda década do século XXI, é marcado pela ascensão da extrema-direita no âmbito da presidência da República, com forte presença no Parlamento e em estreito conluio com o Judiciário, em seu protagonismo nos percursos do Golpe de 2016. 


\section{REVIIStg alm PDUtI}

\} MODELO DE AJUSTE NOS GOVERNOS - CARVALHO, A. M. P.; RODRIGUES JÚNIOR, N. S. \}

DOI: $10.12957 /$ REP.2019.45245

As Forças Armadas ocupam um crescente espaço na institucionalidade brasileira, com a possibilidade de voltarem ao comando do país, inclusive pela via democrático-eleitoral, considerando ser o General Hamilton Mourão o vice-presidente da República, com forte presença na cena política, neste Brasil do Presente.

Instaura-se um Estado inteiramente voltado para os interesses do capital, a assumir políticas ultraneoliberais, fragilizando, cada vez mais, a soberania nacional. É um Estado autoritário, conservador e reacionário, a desconsiderar pactos e regulações democráticas.

Entendemos ser este um momento-limite da contemporaneidade brasileira, permeado de instabilidades e incertezas, mergulhado no obscurantismo e no reacionarismo, que beira o fascismo político-cultural. Inegavelmente, este difícil momento histórico parece ser a culminância do Golpe de 2016, a expressar a debacle da ideologia da conciliação de classes. Os pactos entre classes parecem impossíveis neste cenário de dominância da direita, a afirmar-se no consenso fundamentalista-religioso, fincado na força das violências e do autoritarismo. 


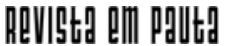

\} MODELO DE AJUSTE NOS GOVERNOS - CARVALHO, A. M. P.; RODRIGUES JÚNIOR, N. S. \}

DOI: $10.12957 /$ REP.2019.45245

\section{Referências}

ALVES, G. A esfinge do neodesenvolvimentismo e a miséria do trabalho no Brasil (2002-2013). In: MACÁRIO, E.; VALE, E. S.; RODRIGUES JR., N. S. (org.). Neodesenvolvimentismo, trabalho e questão social. Fortaleza: Expressão Gráfica e Editora, 2016.

ALVES, G. O minotauro brasileiro. Reforma trabalhista e desenvolvimento histórico do capitalismo no Brasil. Revista do Tribunal Regional do Trabalho da 15a Região, n. 51, 2017. Disponível em: https://juslaboris.tst.jus.br/ bitstream/handle/20.500.12178/125460/2017_alves_giovanni_minotauro brasileiro.pdf? sequence=1\&isAllowed=y. Acesso em: 20 maio 2018.

BRAGA, R. Apresentação. In: OLIVEIRA, F.; BRAGA, R.; RIZEK, C. (org.). Hegemonia às avessas: economia, política e cultura na era da servidão financeira. São Paulo: Boitempo, 2010.

BRAGA, R. O fim do lulismo. In: JINKINGS, I.; DORIA, K.; CLETO, M. (org.). Por que gritamos golpe? Para entender o impeachment e a crise no Brasil. São Paulo: Boitempo, 2016.

BRESSER-PEREIRA, L. C. O novo desenvolvimentismo e a ortodoxia convencional. São Paulo em Perspectiva, v. 20, n. 3, jul./set. 2006.

CARTA MAIOR. Para Mészáros, capitalismo vive uma crise estrutural profunda. 21 jun. 2011. Disponível em: https://www.cartamaior.com.br/?/Editoria/ Politica/Para-Meszaros-capitalismo-vive-uma-crise-estrutural-profunda/4/ 17047. Acesso em: 10 ago. 2018.

CARVALHO, A. M. P. Transformações do Estado na América Latina em tempos de ajuste e resistências: governos de esquerda em busca de alternativas. In: CARLEIAL, A. N. (org.). Projetos nacionais e conflitos na América Latina. Fortaleza: Edições UFC, 2006.

CARVALHO, A. M. P. Análise de conjuntura e crise do Estado. Aula inaugural no campo das Políticas Públicas. Fortaleza, 2017a.

CARVALHO, A. M. P. Democracia, participação e seguridade. In: SEMINÁRIO DE POLÍTICA DE ASSISTÊNCIA SOCIAL EM MARACANAÚ, 2, Maranacaú. Ceará: Secretaria de Assistência Social e Cidadania, 2017b.

CARVALHO, A. M. P. Brasil finais de 2018/limiar 2019 - Consumação do Golpe 2016, autoritarismo e guerra de valores no contexto de uma democracia formal: (re)invenção da resistência como exigência do nosso tempo. Análise de Conjuntura - Esplar, Fortaleza, 2018.

CARVALHO, A. M. P.; GUERRA, E. C. O Brasil no século XXI nos circuitos da crise do capital: o modelo brasileiro de ajuste no foco da crítica. Revista de Políticas Públicas, v. 19, 2015. Disponível em: http://www.redalyc.org/ articulo.oa?id=321143201003. Acesso em: 20 jul. 2017. 


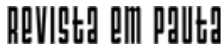

\} MODELO DE AJUSTE NOS GOVERNOS - CARVALHO, A. M. P.; RODRIGUES JÚNIOR, N. S. \}

DOI: $10.12957 /$ REP.2019.45245

CARVALHO, A. M. P.; GUERRA, E. C. Brasil no século XXI na geopolítica da crise: para onde apontam as utopias? Revista de Políticas Públicas, n. especial, nov. 2016. Disponível em: http://www.periodicoseletronicos. ufma.br/index.php/rppublica/article/viewFile/5978/3609. Acesso em: 15 jan. 2018.

CARVALHO, A. M. P.; MILANEZ, B.; GUERRA, E. C. Rentismoneoextrativismo: a inserção dependente do Brasil nos percursos do capitalismo mundializado (1990-2017). In: RIGOTTO, R. M.; AGUIAR, A. C. P.; RIBEIRO, L. A. D. (org.). Tramas para a justiça ambiental: diálogos de saberes e práxis emancipatórias. Fortaleza: Edições UFC, 2018.

CHESNAIS, F. A mundialização do capital. São Paulo: Xamã, 1996.

COUTINHO, C. N. A hegemonia da pequena política. In: OLIVEIRA, F.; BRAGA, R.; RIZEK, C. (org.). Hegemonia às avessas: economia, política e cultura na era da servidão financeira. São Paulo: Boitempo, 2010.

HARVEY, D. O enigma do capital: e as crises do capitalismo. São Paulo: Boitempo, 2011.

HARVEY, D. O neoliberalismo é um projeto político. 29 jul. 2016. Disponível em: https://www.esquerda.net/artigo/david-harvey-o-neoliberalismo-e-umprojeto-politico/43872. Acesso em: 19 jun. 2018

IPEA. Brasil em desenvolvimento: Estado, planejamento e políticas públicas. 2009. Disponível em: http://www.ipea.gov.br/bd/pdf/2009/Livro_Brasil DesenvEN_Vol04.pdf. Acesso em: 15 jun. 2018

MACÁRIO, E.; RODRIGUES JR., N. S.; SILVA, R. A. Trabalho e questão social no Brasil contemporâneo: para uma crítica ao neodesenvolvimentismo. In: MACÁRIO, E.; VALE, E. S.; RODRIGUES JR., N. S. (org.). Neodesenvolvimentismo, trabalho e questão social. Fortaleza: Expressão Gráfica e Editora, 2016.

MARINI, R. M. Dialética da dependência. In: TRASPADINI, R.; STEDILE, J. P. (org.). Ruy Mauro Marini - Vida e obra. São Paulo: Expressão Popular, 2005.

MÉSZÁROS, I. O poder da ideologia. São Paulo: Boitempo, 2004.

MÉSZÁROS, I. Crise estrutural do capital. São Paulo: Boitempo, 2009.

OLIVEIRA, F. Hegemonia às avessas. Piauí, Rio de Janeiro, n. 4, jan. 2007.

OLIVEIRA, F.; BRAGA, R.; RIZEK, C. (org.). Hegemonia às avessas: economia, política e cultura na era da servidão financeira. São Paulo: Boitempo, 2010.

OSÓRIO, J. América Latina: o novo padrão exportador de especialização produtiva. In: FERREIRA, C.; OSORIO, J.; LUCE, M. S. (org.). Padrão de reprodução do capital. São Paulo: Boitempo, 2012. 


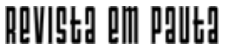

\} MODELO DE AJUSTE NOS GOVERNOS - CARVALHO, A. M. P.; RODRIGUES JÚNIOR, N. S. \}

DOI: $10.12957 /$ REP.2019.45245

PAULANI, L. M. A inserção da economia brasileira no cenário mundial: uma reflexão sobre a situação atual à luz da História. Boletim de Economia e Política Internacional, Brasília, n. 10, abr./jun. 2012a.

PAULANI, L. M. A dependência redobrada. Le Monde Diplomatique Brasil, São Paulo, 2012 b.

PAULANI, L. M. Uma ponte para o abismo. In: JINKINGS, I.; DORIA, K.; CLETO, M. (org.). Por que gritamos golpe? Para entender o impeachment e a crise no Brasil. São Paulo: Boitempo, 2016.

POCHMANN, M.; BORGES, A. "Era FHC": a regressão do trabalho. São Paulo: Anita Garibaldi, 2002.

RODRIGUES JR., N. S.; CARVALHO, A. M. P. Brasil no século XXI: Governo Temer, ofensiva neoliberal e superexploração do trabalho. In: ROCHA, A. R. M. et al. Capitalismo contemporâneo e educação brasileira: aspectos controversos e atuais. Fortaleza: Expressão Gráfica e Editora, 2018.

DOI: $10.12957 /$ rep.2019.45245

Recebido em 29 de abril de 2019.

Aprovado para publicação em 22 de julho de 2019.

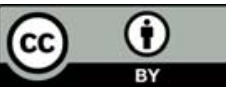

A Revista Em Pauta: Teoria Social e Realidade Contemporânea está licenciada com uma Licença Creative Commons Atribuição 4.0 Internacional. 